\title{
Toxic effect of heavy metals on aquatic environment
}

\author{
Joseph BABY, Justin S. RAJ *, Edwin T. BIBY, P. SANKARGANESH, \\ M.V. JEEVITHA, S.U. AJISHA and Sheeja S. RAJAN \\ Interdisciplinary Research Unit, Malankara Catholic College, Mariagiri, Kaliyakkavilai- 629 153- India. \\ *Corresponding author, E-mail: rajstephy6@gmail.com
}

\begin{abstract}
The indiscriminate discharge of industrial effluents, raw sewage wastes and other waste pollute most of the environments and affect survival and physiological activities of target organisms. Metals in particular have a tendency to accumulate and undergo food chain magnification. Heavy metals affect all groups of organisms and ecosystem processes, including microbial activities. The bioaccumulation of trace elements in living organisms and biomagnification in them describes the processes and pathways of these pollutants from one trophic level to another, exhibiting the higher bioaccumulation ability in the organisms concerned. Some of these organisms, like fishes, are consumed by human beings. They could also cause catastrophic diseases like Minamata and Itai-Itai. Remediation approaches such as excavation and land fill, thermal treatment, electroreclamation and soil capping have been proposed depending on the extension, depth and kind of contamination, but all are expensive and environmentally destructive. Hence, reduction of toxic elements in aquatic environment can be progressively monitored by currently accepted and updated methods.
\end{abstract}

(C) 2010 International Formulae Group. All rights reserved.

Keywords: Heavy metals, effluents, Minamata, Itai-itai, Remediation, antacids.

\section{INTRODUCTION}

Heavy metal pollution is known to be the cause of various diseases globally, such as the minamata disease (organic mercury poisoning), iItai-itai disease (cadmium poisoning), arsenous acid poisoning, and airpollution-related asthma (Matsuo, 2003). Marine ecosystems are highly complex, dynamic and subject to many internal and external relationships that are subject to change over time. The pollutants that enter the inshore waters and estuaries create serious problems causing extensive damage to the life and activities of the living aquatic organisms and even to mass mortality. Among the pollutants, accumulation of heavy metals in marine ecosystems is of global importance.
Significant contributions have been made with reference to oceanic and coastal distribution of various heavy metals. The natural aquatic systems may extensively be contaminated with heavy metals released from domestic, industrial and other man-made activities (Velez and Montoro, 1998; Conacher, et al., 1993). Heavy metal contamination may have devastating effects on the ecological balance of the recipient environment and a diversity of aquatic organisms (Farombi, et al., 2007; Vosyliene and Jankaite, 2006; Ashraj, 2005). Among animal species, fishes are the inhabitants that cannot escape from the detrimental effects of these pollutants (Olaifa et al., 2004; Clarkson, 1998; Dickman and Leung, 1998). Fishes are widely used to 
evaluate the health of aquatic ecosystems because pollutants build up in the food chain and are responsible for adverse effects and death in the aquatic systems (Farkas et al., 2002; Yousuf and El-Shahawi, 1999). The heavy metals generally, enter the aquatic environment through atmospheric deposition, erosion of geological matrix or due to anthropogenic activities caused by industrial effluents, domestic sewage and mining wastes. The metal contaminants in aquatic systems usually remain either in soluble or suspension form and finally tend to settle down at the bottom or are taken up by the organisms. The progressive and irreversible accumulation of these metals in various organs of marine creatures leads to metal related diseases in the long run because of their toxicity, thereby endangering the aquatic biota and other organisms. Fishes being one of the main aquatic organisms in the food chain may often accumulate large amounts of certain metals. Directly acting or synergistically acting metals like $\mathrm{Fe}, \mathrm{Zn}, \mathrm{Pb}$, $\mathrm{Cd}, \mathrm{Cu}$ and $\mathrm{Mn}$ are common toxic pollutants for fish. The bioaccumulation of trace elements in living organisms and biomagnification in them describes the processes and pathways of these (possible) pollutants from one trophic level to another, exhibiting the higher bioaccumulation ability in the organisms concerned. Increasing concentration through the food chain caused higher retention time of toxic substances than that of the other normal food components. "Toxic metals, including "heavy metals," are individual metals and metal compounds that have been shown to negatively affect people's health. In very small amounts many of these metals are necessary to support life. However, in larger amount they become toxic. They may build up in biological systems and become a significant health hazard" (OSHA, 2004).

\section{Heavy metals}

The term heavy metal refers to any metallic chemical element that has a relatively high density and is toxic or poisonous at low concentration. Examples of heavy metals include mercury $(\mathrm{Hg})$, cadmium $(\mathrm{Cd})$, arsenic (As), chromium ( $\mathrm{Cr}$ ), thallium ( $\mathrm{Tl}$ ), and lead $(\mathrm{Pb})$. Heavy metals are natural components of the earth's crust. They cannot be degraded or destroyed. Heavy metals are dangerous because they tend to bioaccumulate. Bioaccumulation means an increase in the concentration of a chemical in a biological organism over time, compared to the chemical's concentration in the environment. Compounds accumulate in living things any time they are taken up and stored faster than they are broken down (metabolized) or excreted. Heavy metals can enter a water supply from industrial and consumer waste, or even from acidic rain, breaking down soils and releasing heavy metals into streams, lakes, rivers and groundwater.

Toxic heavy metals. Heavy metals become toxic when they are not metabolized by the body and accumulate in the soft tissues. Heavy metals may enter the human body through food, water, air, or absorption through the skin when they come in contact with humans in agriculture and in manufacturing, pharmaceutical, industrial, or residential settings. Industrial exposure accounts for a common route of contamination for adults. Ingestion is the most common route of exposure in children (Roberts, 1999). Children may develop toxic levels from the normal hand-to-mouth activity of small children who come in contact with contaminated soil or by actually eating objects that are not food (dirt or paint chips) (Dupler, 2001). Less common routes of exposure are during a radiological procedure, from inappropriate dosing or monitoring during intravenous (parenteral) nutrition, from a broken thermometer (Smith et al., 1997), or from a suicide or homicide attempt (Lupton et al., 1985).

\section{Commonly encountered toxic heavy metals \\ - Arsenic (As) \\ - Lead $(\mathrm{Pb})$ \\ - Mercury $(\mathrm{Hg})$ \\ - Cadmium (Cd) \\ - Iron $(\mathrm{Fe})$}




\section{- Aluminum (Al) Arsenic}

Arsenic is the most common cause of acute heavy metal poisoning in adults and is number 1 on the ATSDR's "Top 20 List." Arsenic is released into the environment by the smelting process of copper, zinc and lead, as well as by the manufacturing of chemicals and glasses. Arsine gas is a common biproduct produced by the manufacturing of pesticides that contain arsenic. Arsenic may also be found in water supplies worldwide, leading to exposure of shellfish, cod, and haddock. Other sources are paints, rat poisoning, fungicides, and wood preservatives. Target organs are the blood, kidneys, central nervous, digestive and skin systems (Roberts, 1999).

\section{Lead}

Lead is number 2 on the ATSDR's "Top 20 List." Lead accounts for most of the cases of pediatric heavy metal poisoning (Roberts, 1999). It is a very soft metal and was used in pipes, drains, and soldering materials for many years. Millions of homes built before 1940 still contain lead (e.g., in painted surfaces), leading to chronic exposure from weathering, flaking, chalking, and dust. Every year, industries produce about 2.5 million tons of lead throughout the world. Most of this lead is used for batteries. The remainder is used for cable coverings, plumbing, and fuel additives. Other uses are as paint pigments and in PVC plastics, x-ray shielding, crystal glass production, and pesticides. Target organs are the bones, brain, blood, kidneys, and thyroid gland (International Occupational Safety and Health Information Centre, 1999; ATSDR ToxFAQs for Lead).

\section{Mercury}

Number 3 on ATSDR's "Top 20 List" is mercury. Mercury is generated naturally in the environment from the degassing of the earth's crust, from volcanic emissions. It exists in three forms: elemental mercury, organic and inorganic mercury. Mining operations, chloralkali plants, and paper industries are significant producers of mercury (Goyer,
1996). Atmospheric mercury is dispersed across the globe by winds and returns to the earth in rainfall, accumulating in aquatic food chains and fish in lakes (Clarkson, 1990). Mercury compounds were added to paint as a fungicide until 1990. These compounds are now banned; however, old paint supplies and surfaces painted with these old supplies still exist. Mercury continues to be used in thermometers, thermostats, and dental amalgam. Many researchers suspect dental amalgam as being a possible source of mercury toxicity (Omura et al., 1996; O Brien, 2001). Medicines, such as mercurochrome and merthiolate, are still available. Algaecides and childhood vaccines are also potential sources. Inhalation is the most frequent cause of exposure to mercury. The organic form is readily absorbed in the gastrointestinal tract (90-100\%); lesser but still significant amounts of inorganic mercury are absorbed in the gastrointestinal tract $(7-15 \%)$. Target organs are the brain and kidney (Roberts, 1999).

\section{Cadmium}

Cadmium is a byproduct of the mining and smelting of lead and zinc and is number 7 on ATSDR's "Top 20 list." It is used in nickelcadmium batteries, PVC plastics, and paint pigments. It can be found in soil because insecticides, fungicides, sludge, and commercial fertilizers that use cadmium in agriculture. Cadmium may be found in reservoirs containing shellfish. Cigarettes also contain cadmium. Lesser-known sources of exposure are dental alloys, electroplating, motor oil and exhaust. Inhalation accounts for $15-50 \%$ of absorption through the respiratory system; $2-7 \%$ of ingested cadmium is absorbed in the gastrointestinal system. Target organs are the liver, placenta, kidneys, lungs, brain and bones (Roberts, 1999).

Iron

Discussion of iron toxicity in this protocol is limited to ingested or environmental exposure. Iron does not appear on the ATSDR's "Top 20 List," but it is a heavy metal of concern, particularly because ingesting dietary iron supplements may acutely poison young children (e.g., as few as 
five to nine $30-\mathrm{mg}$ iron tablets for a $30-\mathrm{lb}$ child). Ingestion accounts for most of the toxic effects of iron because iron is absorbed rapidly in the gastrointestinal tract. The corrosive nature of iron seems to further increasing the absorption. Most overdoses appear to be the result of children mistaking red-coated ferrous sulfate tablets or adult multivitamin preparations for candy. (Fatalities from overdoses have decreased significantly with the introduction of childproof packaging. In recent years, blister packaging and the requirement that containers with $250 \mathrm{mg}$ or more of iron have child-proof bottle caps have helped reduce accidental ingestion and overdose of iron tablets by children). Other sources of iron are drinking water, iron pipes, and cookware. Target organs are the liver, cardiovascular system, and kidneys (Roberts, 1999).

\section{Aluminum}

Although aluminum is not a heavy metal (specific gravity of 2.55-2.80), it makes up about $8 \%$ of the surface of the earth and is the third most abundant element (ATSDR ToxFAQs for Aluminum). It is readily available for human ingestion through the use of food additives, antacids, buffered aspirin, astringents, nasal sprays, and antiperspirants; from drinking water; from automobile exhaust and tobacco smoke; and from using aluminum foil, aluminum cookware, cans, ceramics, and fireworks (ATSDR ToxFAQs for Aluminum). Studies began to emerge about 20 years ago suggesting that aluminum might have a possible connection with developing Alzheimer's disease when researchers found what they considered to be significant amount of aluminum in the brain tissue of Alzheimer's patients. Although aluminum was also found in the brain tissue of people who did not have Alzheimer's disease, recommendations to avoid sources of aluminum received widespread public attention. As a result, many organizations and individuals reached a level of concern that prompted them to dispose of all their aluminum cookware and storage containers and to become wary of other possible sources of aluminum, such as soda cans, personal care products, and even their drinking water (Anon., 1993). Target organs for aluminum are the central nervous system, kidney, and digestive system.

\section{Causes of heavy metal pollution}

Heavy metal pollution can arise from many sources but most commonly arises from the purification of metals, e.g., the smelting of copper and the preparation of nuclear fuels. Electroplating is the primary source of chromium and cadmium. Through precipitation of their compounds or by ion exchange into soils and muds, heavy metal pollutants can localize and lay dormant. Unlike organic pollutants, heavy metals do not decay and thus pose a different kind of challenge for remediation. Currently, plants or microrganisms are tentatively used to remove some heavy metals such as mercury. Plants which exhibit hyper accumulation can be used to remove heavy metals from soils by concentrating them in their bio matter. Some treatment of mining tailings has occurred where the vegetation is then incinerated to recover the heavy metals. Heavy metals like lead, mercury, iron, cadmium, aluminum and magnesium are present in water sources. If these metals are present in the sediment, these reach the food chain through plants and aquatic animals. This causes heavy metal poisoning in case the level in the water is very high.

\section{Smelting}

Smelting is a form of extractive metallurgy; its main use is to produce a metal from its ore. This includes iron extraction (for the production of steel) from iron ore, and copper extraction and other base metals from their ores. Smelting uses heat and a chemical reducing agent, commonly a fuel that is a source of carbon such as coke, or in earlier times charcoal, to change the oxidation state of the metal ore. The carbon or carbon monoxide derived from it removes oxygen from the ore to leave the metal. The carbon is thus oxidized, producing carbon dioxide and carbon monoxide. As most ores are impure, it is often necessary to use flux, such as 
limestone, to remove the accompanying rock gangue as slag. Plants for the electrolytic reduction of aluminium, while not using carbon, are also generally referred to as smelters.

\section{Electroplating}

Electroplating is a plating process that uses electrical current to reduce cations of a desired material from a solution and coat a conductive object with a thin layer of the material, such as a metal. Electroplating is primarily used for depositing a layer of material below a desired property (e.g., abrasion and wear resistance, corrosion protection, lubricity, aesthetic qualities, etc.) to a surface that otherwise lacks that property. Another application uses electroplating to build up thickness on undersized parts.

\section{Industrial effluents}

Water pollution is caused due to the discharge of harmful chemicals and compounds into water, which leaves the water unsuitable for drinking and other purposes. This renders the water useless for humans, and also endangers aquatic life. Water pollution is caused by emission of domestic or urban sewage, agricultural waste, pollutants and industrial wastes into water bodies. Nowadays, one of the main sources of water pollution is the waste material discharged by industrial units, known as industrial effluents. Waste materials like acids, alkalies, toxic metals, oil, grease, dyes, pesticides and even radioactive materials are poured into the water bodies by many industrial units (Figure 1). Some other important pollutants include polychlorinated biphenyl (PCB) compounds, lubricants and hot water discharged by power plants. The pollutants unloaded into the water bodies usually dissolve or remain suspended in water. Sometimes, they also accumulate on the bottom of the water bodies. These harmful pollutants are a major contributor to many grave diseases such as diarrhoea, cholera, hepatitis, dysentry and salmonellasis. Besides, many of the pollutants are also carcinogenic i.e. they can cause cancer. Some pollutants like sodium can cause cardiovascular diseases, while mercury and lead cause nervous disorders. DDT is another toxic material which can cause chromosomal changes.

\section{Metal uptake by aquatic organisms}

Metal uptake by aquatic organisms is a two-phased process, which involves initial rapid adsorption or binding to the surface, followed by a slower transport into the cell interior (Crist et al., 1988). In epithelial tissues the last step is the rate-limiting factor in transepithelial movement of metals (Foulkes, 1988). Transport of metals into the intracellular compartment may be facilitated by either diffusion of the metal ion across the cell membrane or by active transport by a carrier protein (Brezonik et al., 1991).

\section{Metal uptake by gills}

Gill surfaces are the first target of water-borne metals (Spicer and Weber, 1991). The micro-environment of the gill surface consists of an epithelial membrane which primarily contains phospholipids covered by a mucous layer (Bolis et al., 1984; Van de Winkel et al., 1986). The constituents of the external gill surface have a $\mathrm{pK}$ value of 3.6 (Reid, 1990) and at environmentally relevant $\mathrm{pH}$ values $(\mathrm{pH}>5)$, these constituents of the gill epithelia will be fully ionised, resulting in negatively charged gill surfaces and potential gill-metal interaction sites (Reid and MacDonald, 1991). The $\mathrm{pK}$ value refers to the condition where the anion concentration (A-) is equal to the concentration of the conjugate (HA). The extent of metal interaction with biological complexes varies widely among metals and has resulted in the development of a number of approaches to provide a measure of predictive relationships for these complexation patterns. Two of the most widely used approaches are:

- Correlations based on the metal ion size (the ionic radius or a function of charge: radius ratio),

- Correlations based on metal ion electronegativity (Nieboer and Richardson, 1980; Brezonik et al., 1991).

According to Nieboer and Richardson (1980) the relative binding affinity of a metal 
for biological ligands is a function of the tendency of a metal to form ionic vs. covalent bonds (metal electronegativity), as well as the chemistry of the particular ligand. Therefore, metal binding to gill surfaces could primarily be determined by the ionic interactions with the epithelial tissue (Reid and MacDonald, 1991). Ionic interactions are characteristic of oxygen-rich ligands, suggesting that the oxygen-rich centres of the carboxylate, sulphate and phosphate groups act as metal receptors, whereas covalent interactions typically bind to nitrogen or sulphur rich ligands, which are characteristic of sulphydryl, thioether, nitrogen and amino groups (Reid and MacDonald, 1991).

\section{Metal uptake into the plasma}

Once in the bloodstream, metals are transported by binding to specific plasma proteins. Bentley (1991) isolated a serum albumin in channel catfish (Ictalurus puntatus), which appeared to be specific for $\mathrm{Zn}$ binding. These results suggest that a single protein with steric factors, which influence access to binding sites, or the involvement of non-sulphydryl, non-electrostatic sites such as imidazole groups, was responsible for specificity towards $\mathrm{Zn}$ binding. The presence of such a protein would, therefore, prevent more competitive metals from competing for binding sites in the plasma. Furthermore, this protein maintained physiologically active "free" Zn at low concentrations despite the high total $\mathrm{Zn}$ concentration in the plasma. Fletcher and Fletcher (1978) and Bentley (1991) found that nearly all the $\mathrm{Zn}$ bound to plasma proteins was freely exchangeable. Iron is bound to the protein transferrin in the plasma (Guyton, 1982), which has a low binding affinity for $\mathrm{Cu}$ and $\mathrm{Zn}$ (Bentley, 1991). Studies by Grobler-van Heerden et al. (1991) showed that T. sparrmanii also concentrated $\mathrm{Fe}$ to finite levels before elimination of the excess metals took place. Noel-Lambot et al. (1978) showed that exposure of Anguilla anguilla to elevated ambient $\mathrm{Cu}$ induced the production of MT, which is responsible for binding $\mathrm{Cu}$, in gill tissue.

\section{Metal uptake by the liver}

The liver is the main organ for metal regulation in mammals and it appears to have a similar function in fish (Heath, 1987). Exposure to metals results in induction of MT production and subsequent binding of metals to the protein (Hogstrand and Haux, 1991).

According to Brown and Parsons (1978) MT always exists in a metal-saturated form and, therefore, the formation of MT is a de novo process. According to Pickering (1993) the stress response can be regarded as a mechanism that enables fish to avoid or overcome potentially threatening or harmful situations. Even though the response may vary according to different circumstances, there appears to be a common element in response to all forms of environmental stress. This involves the activation of the sympatheticochromaffin system to release catecholamines and the hypothalamic-pituitary-interrenal axis for secretion of corticosteroid hormones into the circulatory system. Secretion of catecholamines is particularly rapid in response to respiratory stress and promotes the survival of fish by increasing the blood supply to the gills, increasing the bloodoxygen carrying capacity and increasing intermediate metabolism to provide a readily accessible energy supply (Pickering, 1993). Catecholamines induce glycogenolysis (Klee et al., 1990), gluconeogenesis (Morata et al., 1982) and lipid mobilisation (Sheridan, 1987) in the liver of fish. It is, therefore, highly probable that catecholamines (or other hormones) are responsible for inducing other adaptive changes in liver tissue. It is intriguing to speculate that internal metal fluxes may have taken place in reaction to stress-induced secretion of hormones, thereby resulting in the release of the naturally bound metals in the liver. These metals were most probably depurated through bilary excretion into the intestine and/or renal excretion.

\section{Bioaccumulation}

Bioaccumulation is the accumulation of contaminants by species in concentrations that are orders of magnitude higher than in the surrounding environment. Bioaccumulation is 
the sum of two processes: bioconcentration and biomagnification. Bioconcentration is the direct uptake of a substance by a living organism from the medium (e.g., water) via skin, gills or lungs, whereas biomagnification results from dietary uptake. Fish that actively filter large amounts of water through their gills are subject to a much higher bioconcentration. Additionally, biomagnification takes place in predatory organisms. The heavy metals of the prey are transferred to the predator (Figure 2).

\section{Effects of heavy metal poisoning}

At the right concentrations, many metals are essential to life. In excess, these same chemicals can be poisonous. Similarly, chronic low exposure to heavy metals can have serious health effects in the long run. The main threats to human well-being are associated with lead, arsenic, cadmium and mercury, and these substances are targeted by international legislative bodies.

Lead poisoning in children causes neurological damage leading to a reduction in intelligence, loss of short term memory, learning disabilities and problems with coordination. Prenatal exposure can cause reduced birth weight and immune suppression or oversensitisation, which could explain why some children develop asthma and allergies (Day, 1998). It has also been suggested that lead can affect behavioural inhibition mechanisms with a consequent increase in violence (Masters, 1998), and that it can contribute to tooth decay (Gil et al., 1996). Many developed countries had significantly reduced lead levels in children by 1992 , mainly by introducing lead-free fuel. The US, for instance, showed a 77 percent reduction (Pirkle et al., 1994), although 2 million children were still at risk (Brody et al., 1994); in Britain, blood-levels of lead have fallen by two third since 1987 (IEH, 1998). However lead pollution levels have been rising in the urban areas of many developing countries, with more than $90 \%$ of the children in some African cities suffering from lead poisoning (Nriagu et al., 1996). The impacts on their development prospects can easily be imagined. Recent work has also found that waste incineration contributes a substantial amount of the lead fallout over urban areas (Chilrud et al., 1999). Most incinerators have been shut in Europe and North America, but they are increasingly used in developing countries, including China and Pakistan, which may help account for this increase.

High concentrations of arsenic in drinking water have been documented in specific parts of Argentina, Canada, Chile, China, Japan, Mexico, the Philippines and the USA. The problem is particularly acute in West Bengal and Bangladesh, where an estimated 30 million people are drinking arsenic-poisoned water (WHO, 1997). Some $62 \%$ of wells supply arsenic-contaminated water above WHO's limits with some containing as much as 400 times the limit (Bagla and Kaiser, 1996). The effects of arsenic include cardiovascular problems, skin cancer and other skin effects, peripheral neuropathy (WHO, 1997) and kidney damage. And yet, one can filter out the arsenic and supply one person with clean water for about 15 US cents per year (Beard, 1998).

Cadmium exposure occurs mainly through cereals and vegetables grown on soils contaminated by mining activities and use of phosphorus fertilizers. Shellfish and animal organs also contain high levels of cadmium. It accumulates in the kidneys and is implicated in a range of kidney diseases (WHO, 1997).

Mercury accumulates at the top of aquatic and marine food chains and fish is the major source of dietary exposure (WHO, 1997). The principal health risks associated with mercury are damage to the nervous system, with such symptoms as uncontrollable shaking, muscle wasting, partial blindness, and deformities in children exposed in the womb. At levels well below WHO limits, it can damage the foetal and embryonic nervous systems with consequent learning difficulties, poor memory and shortened attention spans (Jorgensen et al., 1997). Low-level exposure 
can also adversely affect male fertility (Dickman et al., 1998).

Most of the mercury found in high concentrations in the Everglades in Florida comes from thousands of miles away, traveling on trade winds from Europe and Africa (Zarrella, 1998). Although it appears that less mercury than previously thought is polluting Greenland (Boutron et al., 1998), global transfers of mercury to the poles are still substantial, with base-levels three times what they were two centuries ago. Every spring, a toxic rain of mercury falls on the arctic, at the time when ecosystems are most active (Pearce, 1997c). As a consequence, one in six Greenlanders has potentially harmful blood-levels of mercury, from eating contaminated fish and whales.

\section{Diseases due to Heavy Metal Poisioning Minamata disease}

Minamata disease was first discovered in Minamata city in Kumamoto prefecture, Japan in 1956. It was caused by the release of methyl mercury in the industrial wastewater from the Chisso Corporation's chemical factory, which continued from 1932 to 1968. This highly toxic chemical bioaccumulated in shellfish and fish in Minamata Bay and the Shiranui Sea, which when eaten by the local populace resulted in mercury poisoning. While cat, dog, pig and human deaths continued over more than 30 years, the government and company did little to prevent the pollution (Figure 3).

Symptoms include numbness in the hands and feet, general muscle weakness, narrowing of the field of vision and damage to hearing and speech. In extreme cases, insanity, paralysis, coma and death follow within weeks of the onset of symptoms. A congenital form of the disease can also affect foetus in the womb.

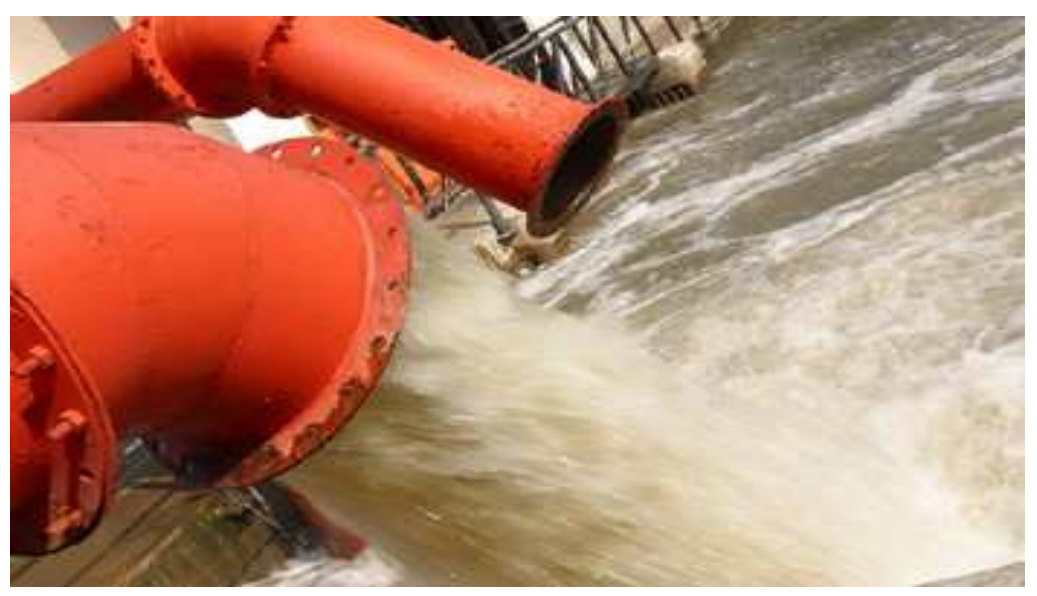

Figure 1: Industrial effluent from industrial unit. 


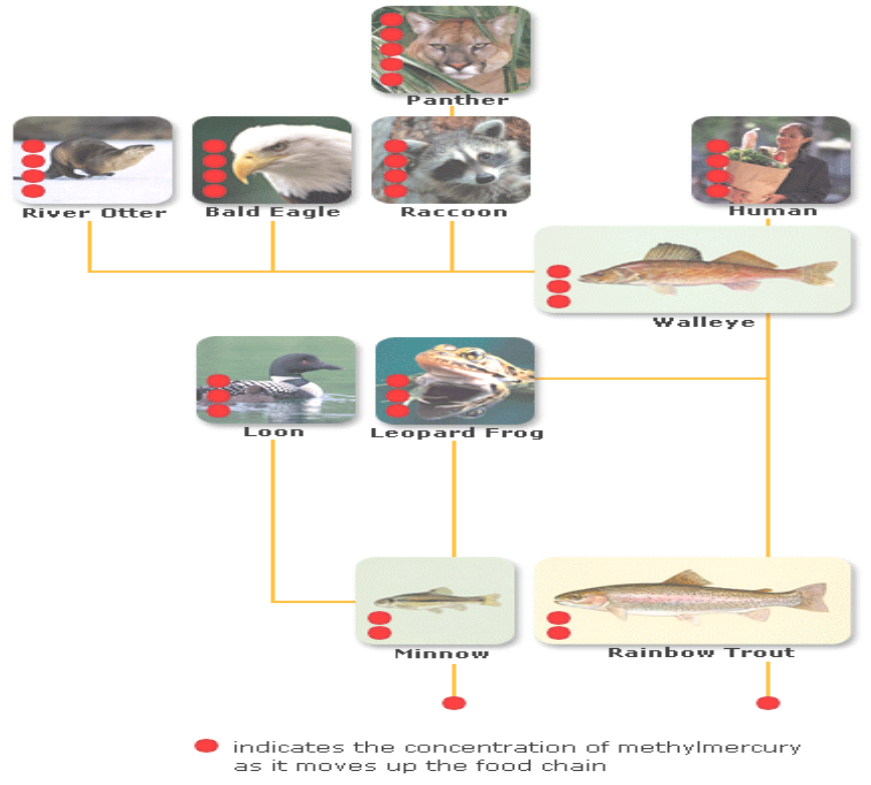

Figure 2: Bioaccumulation of heavy metals from aquatic environment.

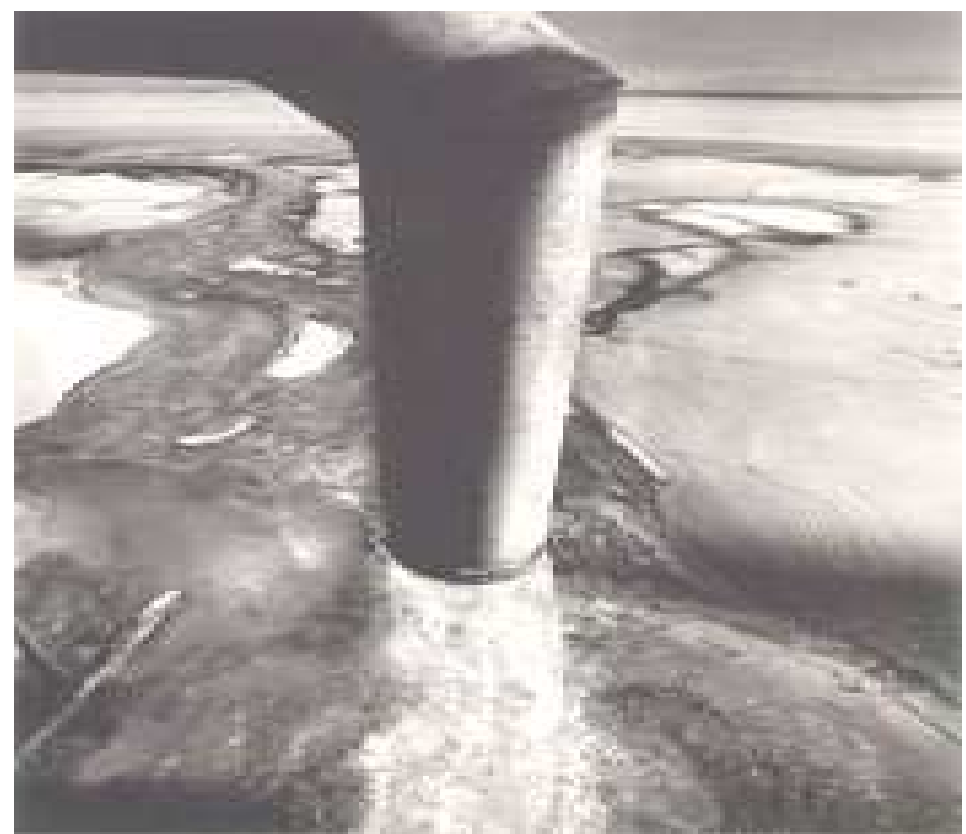

Figure 3: Waste water discharge from the Chisso factory in Minamata. 


\section{Itai-itai disease}

Itai-itai disease was the documented case of mass cadmium poisoning in Toyama Prefecture, Japan. The cadmium poisoning caused softening of the bones and kidney failure. The disease is named for the severe pains caused in the joints and spine. The term itai-itai disease was coined by locals. The cadmium was released into rivers by mining companies in the mountains. The mining companies were successfully sued for the damage. Itai-itai disease is known as one of the four big pollution diseases of Japan.

\section{Cause}

Itai-itai disease was caused by cadmium poisoning due to mining in Toyama Prefecture. The earliest records of mining for gold in the area date back to 710 . Regular mining for silver started in 1589 , and soon thereafter, mining for lead, copper, and zinc began. Increased demand for raw materials during the Russo-Japanese War and World War I, as well as new mining technologies from Europe, increased the output of the mines, putting the Kamioka Mines in Toyama among the world's top mines. Production increased even more before World War II. Starting in 1910 and continuing through 1945 , cadmium was released in significant quantities by mining operations, and the disease first appeared around 1912. Due to the cadmium poisoning, the fish in the river started to die, and the rice irrigated with river water did not grow well. The cadmium and other heavy metals accumulated both in the water and at the bottom of the river. This water was then used to irrigate the rice fields. The rice absorbed heavy metals, especially the cadmium. The cadmium accumulated in the people eating contaminated rice. The mines are still in operation and cadmium pollution levels remain high, although improved nutrition and medical care has reduced the occurrence of Itai-itai disease.

\section{Symptoms}

One of the main effects of cadmium poisoning is weak and brittle bones. Spinal and leg pain is common, and a waddling gait often develops due to bone deformities caused by cadmium. The pain eventually becomes debilitating, with fractures becoming more common as the bone weakens. Other complications include coughing, anemia and kidney failure, leading to death. Recent animal studies have shown that cadmium poisoning alone is not enough to elicit all of the symptoms of Itai-itai disease. These studies are pointing to damage of the mitochondria of kidney cells by cadmium as a key factor of the disease.

\section{Health problems}

Health problems caused by low level chronic exposure to heavy metals may take years to appear. These heavy metals have been linked to conditions ranging from cardiovascular disease, high blood pressure, insomnia, and many more. Much of the exposure to heavy metal pollution has been scientifically proven to be linked to causing free radical damage leading to: Heart attacks, strokes and cancer.

There are also many circulatory diseases other than cardiovascular disease that may not cause death, but can affect the quality of life. Some of these are: Impotency, Alzheimer's Disease, Arthritis, Diabetes, Fatigue, Memory Loss.

Lead poisoning is a serious and very common type of heavy metal poisoning. Symptoms of lead poisoning in children mimic those of Attention Deficit Hyperactivity Disorder (ADHD). Lead poisoning also causes behavioral and learning problems, nervousness, headaches, and many other related symptoms.

\section{Management of heavy metal polluted water}

The commonly used procedures for removing metal ions from aqueous streams include chemical precipitation, lime coagulation, ion exchange, reverse osmosis and solvent extraction (Rich and Cherry, 1987). The process description of each method is presented below.

\section{Reverse osmosis}

It is a process in which heavy metals are separated by a semi-permeable membrane at a pressure greater than osmotic pressure caused by the dissolved solids in polluted 
water. The disadvantage of this method is that it is expensive.

\section{Electrodialysis}

In this process, the ionic components (heavy metals) are separated through the use of semi-permeable ion selective membranes. Application of an electrical potential between the two electrodes causes a migration of cations and anions towards respective electrodes. Because of the alternate spacing of cation and anion permeable membranes, cells of concentrated and dilute salts are formed. The disadvantage is the formation of metal hydroxides, which clog the membrane.

\section{Ultrafiltration}

They are pressure driven membrane operations that use porous membranes for the removal of heavy metals. The main disadvantage of this process is the generation of sludge.

\section{Ion-exchange}

In this process, metal ions from dilute solutions are exchanged with ions held by electrostatic forces on the exchange resin. The disadvantages include: high cost and partial removal of certain ions.

\section{Chemical precipitation}

Precipitation of metals is achieved by the addition of coagulants such as alum, lime, iron salts and other organic polymers. The large amount of sludge containing toxic compounds produced during the process is the main disadvantage.

\section{Phytoremediation}

Phytoremediation is the use of certain plants to clean up soil, sediment, and water contaminated with metals. The disadvantages include that it takes a long time for removal of metals and the regeneration of the plant for further biosorption is difficult.

Hence the disadvantages like incomplete metal removal, high reagent and energy requirements, generation of toxic sludge or other waste products that require careful disposal has made it imperative for a cost-effective treatment method that is capable of removing heavy metals from aqueous effluents.

\section{Biosorption}

The search for new technologies involving the removal of toxic metals from wastewaters has directed attention to biosorption, based on metal binding capacities of various biological materials. Biosorption can be defined as the ability of biological materials to accumulate heavy metals from wastewater through metabolically mediated or physico-chemical pathways of uptake (Fourest and Roux, 1992). Algae, bacteria, fungi and yeasts have proved to be potential metal biosorbents (Volesky, 1986). The major advantages of biosorption over conventional treatment methods include (Kratochvil and Volesky, 1998a).

- Low cost; High efficiency;

- Minimisation of chemical;

- No additional nutrient requirement;

- Regeneration of biosorbent; and

- Possibility of metal recovery.

\section{Conclusion}

The heavy metal concentration, which is above threshold level, could be dangerous to aquatic as well as human health. Ecosystem contamination from heavy metal pollution may damage marine organisms at the cellular level and possibly affect the ecological balance. The aquatic organism takes heavy metals through three ways: the body surface, gills and food. In aquatic environment, microorganisms accumulate metals and consequently, small fish become enriched with the accumulated substances. Predatory fish again, general display higher levels than their prey. Man at the end of food chain suffers from the results of an enrichment having taken place at each trophic level, where less is excreted than ingested. So preventive measures should be taken to reduce the intensity of heavy metal pollution in aquatic environment.

\section{REFERENCES}

Ashraj W. 2005. Accumulation of heavy metals in kidney and heart tissues of Epinephelus microdon fish from the 
Arabian Gulf. Environ. Monit. Assess., 101(1-3): 311-316.

Bagla P, Kaiser J. 1996. India's spreading health crisis draws global arsenic experts. Science, 274(5285): 174-175.

Beard J. 1998. Safe to drink. New Scientist, 28 March, p. 10.

Bentley PJ. 1991. A high-affinity zinc-binding plasma protein in channel catfish (Ictalurus punctatus). Comp. Biochem. Physiol., 100C(3): 491-494.

Boutron CF, Vandal GM, Fitzgerald WF, Ferrari CP. 1998. A 40-year record of mercury in central Greenland snow. Geophysical Research Letters, 24(17): 3315.

Bolis Cl, Cambria A, Fama M .1984. Effects of acid stress on fish gills. In Toxins, Drugs and Pollutants in Marine Mammals, Bolis L, Zadunaisky J, Gilles R (eds). Springer Verlag: Berlin; 122129.

Brezonik Pl, King So, Mach Ce. 1991. The influence of water chemistry on trace metal bioavailability and toxicity to aquatic organisms. In Metal Ecotoxicology: Concepts and Applications, Newman MC, McIntosh AW (eds) Lewis Publishers Inc: Michigan; 1-26.

Brown Da, Parsons Tr. 1978. Relationship between cytoplasmic distribution of mercury and toxic effects to zooplankton and chum salmon, Onchorhynchus keta, exposed to mercury in a controlled ecosystem. J. Fish. Res. Board Canad., 35: $880-884$.

Brody DJ, Pirkle JL, Kramer RA, Flegal KM, Matte TD, Gunter EW, Paschal DC. 1994. "Blood lead levels in the US population - Phase-1 of the 3rd National Health and Nutrition Examination Survey (NHANES-III, 1988 to 1991)." JAMA Journal of the American Medical Association, 272(4): 277-283.

Crist RH, Oberholser K, Schwartz D, Marzoff J, Ryder D, Crist DR. 1988. Interactions of metals and protons with algae. Environ. Sci. Technol., 22: 755-760.
Chilrud SN, RF Bopp, HJ Simpson, JM Ross, EL Shuster, DA Chaky, DC Walsh, CC Choy, LR Tolley, A Yarma. 1999. "Twentieth Century Atmospheric Metal Fluxes into Central Park Lake, New York City". Environmental Science and Technology, 33(5): 657-662.

Clarkson TW. 1998. Human toxicology of mercury. J. Trace. Elem. Exp. Med., 11(2-3): 303-317.

Conacher H B, Page BD, Ryan JJ. 1993. Industrial chemical contamination of foods [Review]. Food Addit. Contam., 10(1): 129-143.

Cox ME, Preda MA. 2005. Trace metal distribution within marine and estuarine sediments of western Moreton Bay, Queensland, Australia: Relation to land use and setting. Geographical Research, 43: 173-193.

Day M. 1998. Lead in the womb. New Scientist, 23 May, p. 7.

Dickman MD, CKM Leung, MKH Leong. 1998. "Hong Kong male subfertility links to mercury in human hair and fish". The Science of the Total Environment, 214(13): 165-174.

Dickman MD, Leung KM. 1998. Mercury and organo chlorine exposure from fish consumption in Hong Kong. Chemosphere, 37(5): 991-1015.

Dupler D. 2001. Heavy metal poisoning. Gale Encyclopedia of Alternative Medicine. Farmington Hills, MI: Gale Group.

Farkas A, Salanki J, Specziar A. 2002. Relation between growth and the heavy metal concentration in organs of bream Abramis brama L. populating lake Balaton. Arch. Environ. Contam. Toxicol., 43(2): 236-243.

Farombi EO, Adelowo OA, Ajimoko YR. 2007. Biomarkers of oxidative stress and heavy metal levels as indicators of environmental pollution in African Cat fish (Clarias gariepinus) from Nigeria ogun river. Int. J. Environ. Res. Public Health, 4(2): 158-165.

Fletcher PE, Fletcher GL. 1978. The binding of zinc to the plasma of winter flounder 
(Pseudopleuronectus americanus): Affinity and specicivity. Canadian $J$. Zool., 56: 114-120.

Foulkes EC. 1988. On the mechanism of transfer of heavy metals across cell membranes. Toxicol., 52: 263-272.

Gil F, Facio A, Villanueva E, Perez ML, Tojo R, Gil A. 1996. The Association of tooth lead content with dental health factors. The Science of the Total Environment, 192(2): 183.

Grobler-Van Heerden E, Van Vuren JHJ, Du Preez HH. 1991. Bioconcentration of atrazine, zinc and iron in the blood of Tilapia sparrmanii (Cichlidae). Comp. Biochem. Physiol.,100C(3): 629-633.

Guyton AC .1982. Human Physiology and Mechanisms of Disease. WB Saunders Company: Philadelphia; 279-283.

Heath Ag. 1987. Water Pollution and Fish Physiology. CRC Press Inc.: Boca Raton; 145.

IEH. 1998. Institute of Environment and Health at Leicester University. Report: Recent UK Blood Lead Surveys. ISBN 1 899110135.

Jorgensen PJ, Dahl R, Grandjean P, Wahl P, White RF, Sorensen N. 1997. Cognitive Deficit in 7-Year-Old Children with Prenatal Exposure to Methylmercury. Neurotoxicology and Teratology, 19(6): 417-428.

Klee M, Eilerson C, Sheridan Ma. 1990. Nutritional state modulates hormonemediated hepatic glycogenolysis in chinook salmon (Oncorhynchus tshawytscha). J. Exp. Zool., 254: 202207.

Lupton G, Kao G, Johnson F, et al. 1985. Cutaneous mercury granuloma: A clinicopathologic study and review of the literature. J. Am. Acad. Derm., 12: 296303.

Masters R. 1998. Environmental Pollution, Neurotoxicity and Criminal Violence. In J. Environmental Toxicology, Rose (ed). Gordon and Breach: London.
Matsuo T. 2003. Japanese experiences of environmental management. Water Science and Technology, 47: 7-14.

Morata P, Vargas Am, Pita ML, SanchezMedina F. 1982. Involvement of gluconeogenesis in hyperglycaemia induced by glucagon, adrenaline and cyclic AMP in rainbow trout. Comp. Biochem. Physiol., 73A: 379-381.

Nieboer E, Richardson DHS. 1980. The replacement of the nondescript term "heavy metals" by a biologically and chemically significant classification of metal ions. Environ. Pollut. (Series B), 1: 3-26.

Noel-Lambot F, Gierday C, Disteche A. 1978. Distribution of $\mathrm{Cd}, \mathrm{Zn}$ and $\mathrm{Cu}$ in liver and gills of the eel Anguilla anguilla with special reference to metallothioneins. Comp. Biochem. Physiol., 61C: 171-187.

Nriagu J, et al. 1996. The science of the total environment, Alison. In Lead Blights the Future of Africa's Children, Motluk (ed). New Scientist, p. 6.

Olaifa FG, Olaifa AK, Onwude TE. 2004. Lethal and sublethal effects of copper to the African Cat fish (Clarias gariepnus). Afr. J. Biomed. Res., 7: 65-70.

Osha. 2004. Safety and Health Topics: Toxic Metals. U.S. Dept. of Labor, Occupational Safety and Health (OSHA) [accessed July 3, 2006].

Pearce Fred. 1997c. Mercurial storms rage in the Arctic. New Scientist, 21 June, p.17.

Pickering AD .1993. Endocrine-induced pathology in stressed salmonid fish. Fish. Res., 17: 35-50.

Pirkle JL, Debra J, Brody EW, Gunter RA, Kramer DC, Paschal KM, Flegal, Matte TD. 1994. The decline in blood lead levels in the United States - The National Health and Nutrition Examination Surveys (NHANES). Journal of the American Medical Association, 272(4): 284-291.

Reid Sd. 1990. Metal-gill surface interactions in Rainbow Trout (Onchorhynchus mykiss). $\quad \mathrm{PhD}$ Thesis, McMaster University, Hamilton. Canada. 
Reid SD, Mcdonald DG. 1991. Metal binding activity of the gills of the rainbow trout (Onchorhynchus mykiss). Can. J. Fish. Aquat. Sci., 48:1061-1068.

Roberts JR.1999. Metal toxicity in children. In Training Manual on Pediatric Environmental Health. Emeryville CA: Children's Environmental Health.

Sheridan MA. 1987. Effects of epinephrine and norepinephrine on lipid mobilization from coho salmon liver incubated in vitro. Endocrinol., 126: 2234-2239.

Smith SR, Jaffe DM, Skinner MA. 1997. Case report of metallic mercury injury. Pediatric Emergency Care, 13: 114-116.

Spicer Ji, Weber Re. 1991. Respiratory impairment in crustaceans and molluscs due to exposure to heavy metals. Comp. Biochem. Physiol., 100C (3): 339-342.

Van de winkel jg, van kuppevelt thmsm, jansen hmj, Lock rac. 1986. Glycosaminoglycans in the skin mucus of rainbow trout (Salmo gairdneri). Comp. Biochem. Physiol., 85B: 473-475.

Velez D, Montoro R. 1998. Arsenic speciation in manufactured seafood products: a review. J. Food. Protect., 61(9): 12401245.

Vole B, sky. 1986. Biosorbent Materials, Biotechnoi. Bioeng Symp., 16: 121-126.

Vosyliene MZ, Jankaite A. 2006. Effect of heavy metal model mixture on rainbow trout biological parameters. Ekologija., 4: 12-17.

WHO. 1997. Health and Environment in Sustainable Development. WHO: Geneva.

Yousuf MH, El-Shahawi A. 1999. Trace metals in Lethrinus lentjan fish from Arabian Gulf: Metal accumulation in Kidney and Heart Tissues. Bull. Environ. Contam. Toxicol., 62(3): 293-300.

Zarrella J. 1998. CNN Environment. WHO: Geneva. 